\title{
Susceptibility of grape varieties to esca disease
}

\author{
Michele Borgo $^{1}$, Gianluca Pegoraro ${ }^{2}$, and Eugenio Sartori ${ }^{2}$ \\ ${ }^{1}$ Consultant Vivai Cooperativi Rauscedo, via Croce, 59, 30150 Povegliano (Treviso), Italy \\ ${ }^{2}$ Vivai Cooperativi Rauscedo, via Udine, 39, 33090 Rauscedo (Pordenone), Italy
}

\begin{abstract}
In the scion wood mother block belonging to Vivai Cooperativi Rauscedo (VCR) the surveys on esca disease have been performed for decades, and the symptomatic plants are uprooted every year. We hereby present and discuss the survey results relating to a group of vines planted in 1995-2006. The first symptoms of esca appeared in 10-12 year-old vines; only in more recent times the disease has appeared invines of 6-8 years. Esca affects more white grape varieties than black varieties. Within each type of grape,it was possible to identify a number of varieties with lower esca incidence than other varieties, which are affected with a very high incidence, in some cases more than $50 \%$ of plants eradicated in the oldest vineyards. The genetic component has proved to be crucial for the varietal susceptibility to expression of esca symptoms; this aspect should be taken into account in the prevention and prophylaxis actions aimed to the limitation of the risks associated with vine trunk decay.
\end{abstract}

\section{Introduction}

In the last 50 years and more, esca epidemics are rising in all wine-producing countries, as amply demonstrated in many works and reported in the international literature. Recent studies and etiological research have allowed us to identify the presence of different fungal species, both in diseased vines andin those free from symptoms that are generally associated with esca syndrome, involved in grapevine trunk diseases. It is well-known that in the vineyards the fungal population modifies and specializes with the passing of years due to environmental and climatic conditions. The esca syndrome is complex, irregular in its onsetsduring the years, largely dependent on climate(as, the winter frosts or the summer rainfall), soil, and agro-technical conditions. The information on genetical susceptibility are lacking and are limited to a small number of varieties, often assessed in different environmental and climatic conditions and limited to a small number of plants. With this work we want to make our contribution to knowledge on varietal susceptibility of Vitis vinifera, as we've been able to assess the incidence of esca symptoms in about two hundred varieties of vines, all grown in the same site, so that to leave out the environmental variable.

\section{Methodology}

The survey was conducted in the Vivai CooperativiRauscedo's (VCR) scion wood mother block (MB), located in Fossalon di Grado (Gorizia), in the North-East of Italy. This center was set up in 1995, and since then it has gradually expanded, as shown in Picture 1. The vineyard collects wine grape varieties and, marginally, table grape varieties, listed the National Register of vine varieties, and some foreign varieties.

At present, there are about 156,000 vines of 195 varieties, many of which expressed withseveral clones, up to form a population of 495 clones from different national and foreign holders. In general, for every variety and clone there are 310 plants or multiples. The vines are mainly grafted on K5BB, SO4, 1103P or, marginally, on other rootstocks. The soil is homogeneous, silty-clayey. The plant spacing is $3 \times 1 \mathrm{~m}$.; the training system is a cordon on low espalier, with grassing between the rows and weeding on the rows. Given the peculiarities of the vineyard, pruning is manual and is carried out in midwinter, so to foster the production of optimal wood for grafting; in spring, the shoots are put on posts with the purpose to promote the maturation of the wood. The pest control focuses on the minimization of fungal diseases and insect attacks.Since the first year of planting all the vinesundergo regular checksto detect any disease, transmittable through grafting or air infections.

Since 2006, following the emergence of the first onsets of esca in some plants of the oldest vineyards, all the vines showing symptoms of the diseasehave been uprooted. This work has allowed us to monitor the evolution of esca over the years and calculate its overall incidence for each variety, net of other diseases and/or die-offs.

Here we are reporting and discussing the data related to the oldest vineyards, planted in 1995-2006 years. We have analyzed 85 varieties, of which 40 white-berried and 45 black-berried, for a total of 44,860 vines, of which 19,334 white and 25,526 black. As the vineyards have been planted gradually during the years, in order to enable a more significant comparison on varietal susceptibility to esca, the plantation periods have been grouped into three clusters of four years each: $1=$ period 1995-98 $(9,414$ vines); 2 = period $1999-2002$ (21,222 vines); $3=$ period 2003-06 (14,224 vines).

\section{Results and considerations}

The dynamics of the uprooting of the vines, following the annual symptoms of esca, lead us to quantify the 


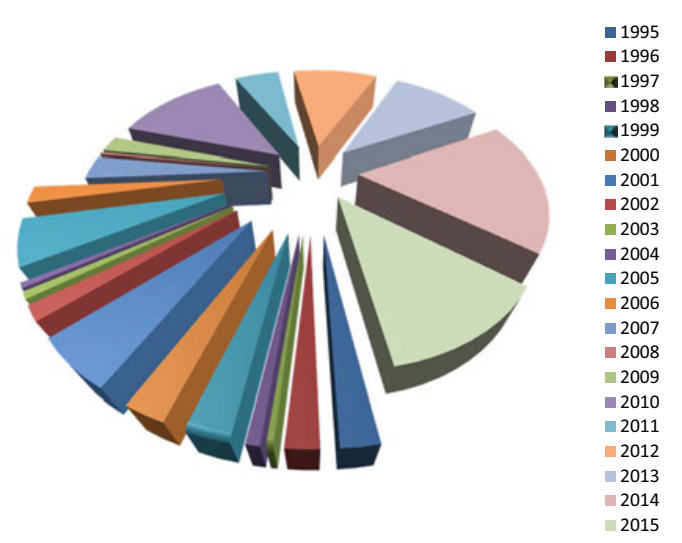

Picture 1. Dynamics of VCR MB vineyard plantations in Fossalon di Grado during the period 1995-2015.

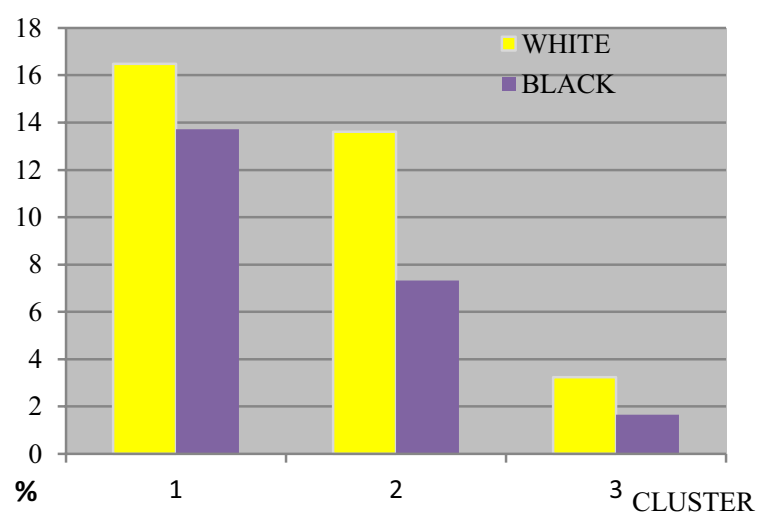

Picture 2. Percentage of vines with esca symptoms in the three clusters for white or black wine.

cumulative disease index over the period 2006-2015. With regard to the first two series with the oldest vines, the white varieties showhigher average values of disease incidence than blackvarieties; the gap is wider in the 1995-1998 series (Picture 2).

The survey of the disease course for each type of grape and the data recorded during the ten years of investigation have highlighted that the vines of esca symptoms are almost absent in the first 6-8 years of age of the vines; the first symptoms usually occur and increase in plants older than 10-12 years (Picture 3 ). In all the clusters, the average incidence of the esca disease is higher in whiteberried varieties thanin black-berried varieties.

Within the white grape and the black grape varietiesit was then possible to identify somevarieties with high tolerance to esca, to the point of being free or little affected by symptoms also on 20 year-old plants. Otherwise, we have recorded a long list of diseased varieties that needed to be uprooted to an extent of more than $50 \%$. In an intermediate position,we can find the majority of the examined varieties (Table $1 \mathrm{a}, \mathrm{b}$ ). In the case of varieties with more clones and planted at different times, we have not always found a linear behavior. Indeed, we have observed high rates of diseased vines also on relatively young vines or vice-versa. No influence on epidemics appeared to depend on the rootstock (K5BB, SO4, 1103P, $110 \mathrm{R}$ ), on the type of grafting (woody or herbaceous) and on the manufacturer of the vines (pre-propagator).

The data on cumulative esca, expressed in final percentage of uprooted vines, bring into clear evidence

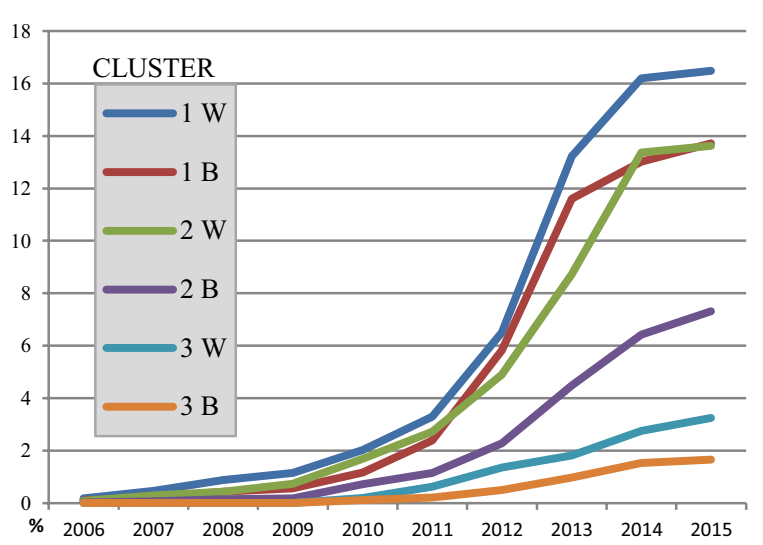

Picture 3. Dynamics of esca accumulation (average \% of uprooted plants) during 2006-2015 in the 3 clusters and for each type of cultivar (white or black).

that for the varieties under examination there is a wide genetic variability towards esca. It is therefore evident that the genetic component may prevail on environmental and cultural factors, whereas the vintage factor can influence the virulence of esca disease, as climatic variables, related to the intensity of the rains and to summer temperatures, can affect the intensity of symptoms and the incidence of vines with symptoms regardless of the age of the plants.

For a better understanding of the grape genetic influence to esca, a preliminary and partial study was started to evaluate the relationship between varietal susceptibility to esca and the presence of some organoleptic compounds in wines from micro-vinification. Limited to a few black grape variety, it was observed that a large part of the varieties with higher values of total polyphenols are classified among those with lower rates of disease and vice versa. Only cv Croatina, Cabernet Sauvignon, Sangiovese and Lambrusco Salamino have differentiated from other varieties.

\section{Conclusions}

Globally, the impact of esca disease around world is an issue of great importance because of the negative effects that it engenders on the longevity of the vineyards, and for the economic consequences due to production losses, which increase with respect to the incidence of diseased, dead and eradicated vines. Prophylaxis and care actions, put into practice by some growers, have not reached satisfactory levels, yet. The low importance that was given so far to varietal susceptibility is being revalued with this preliminary study, by supporting and implementing some of the previous achievements highlighted by some authors also in the past period [1-4].

Based on the early results reported here, we highlight the significant positive role played against esca by many black grape varieties, in particular when rich in polyphenols, as it has resulted in the cv. Aglianico Taurasi, Aglianico del Vulture, Aleatico, Franconia, Lagrein, Nebbiolo, Raboso Veronese, Montepulciano, Petit Verdot, Pinot Noir, Refosco Peduncolo Rosso; just as it has arisen in white varieties, such as cv Arneis, Cortese, Fiano, Grenache Blabc, Pinot Blanc, Riesling Italico, Trebbiano d'Abruzzo, Verdicchio, Verduzzo Friulano. 
Table 1. Incidence $\%$ of esca-affected plants survey on the varieties planted in two time series $\left(\mathrm{I}^{\circ}=1995-98\right.$; $\left.\mathrm{II}^{\circ}=1999-2002\right)$.

\begin{tabular}{|l|c|c|}
\hline White grapes & Cluster I $^{\circ}$ & Cluster II $^{\circ}$ \\
\hline Fiano & & 0 \\
Trebbiano Abruzzo & & 0 \\
Grenache Blanc & 0,37 & \\
Verduzzo Trevigiano & 0,65 & \\
Arneis & & 0,81 \\
Passerina & & 1,29 \\
Riesling Italico & & 1,29 \\
Cortese & & 1,29 \\
Verdiso & & 3,23 \\
Malvasia Chianti & 3,23 \\
Pinot Bianco & 3,7 & 6,13 \\
Pinot Grigio & & 4,52 \\
Malvasia Aromatica & 5,2 & 15,1 \\
Moscato Bianco & & 5,6 \\
Verduzzo Friulano & 6 & 0,32 \\
Chardonnay & & 6,8 \\
Matilde (Table Grape) & & 7,1 \\
Trebbiano Toscano & & 12,9 \\
Moscato Giallo & & 15,2 \\
Grechetto Orvieto & & 2,9 \\
Vermentino & 16,5 & 16,8 \\
Biancame & & 25,85 \\
Traminer & & 36,67 \\
Malvasia Istriana & 26,1 & 30,32 \\
Tocai Friulano & 26,45 & 31,3 \\
Manzoni Bianco & & \\
Müller Thurgau & & \\
Glera & & \\
Italia (Table Grape) & 33,23 & \\
Grechetto Todi & & \\
Riesling B & 45,48 & \\
Albana & 52,9 & \\
& & \\
\hline
\end{tabular}

\begin{tabular}{|c|c|c|}
\hline Black grapes & ${\text { Cluster } \mathrm{I}^{\circ}}^{\circ}$ & ${\text { Cluster } \text { II }^{\circ}}^{\circ}$ \\
\hline Aglianico Taurasi & 0 & 0,16 \\
\hline Merlot & & 0,5 \\
\hline Raboso Veronese & 0,65 & \\
\hline Petit Verdot & 0,65 & \\
\hline Montepulciano & 0,65 & \\
\hline Aglianico del Vulture & & 0,65 \\
\hline Syrah & & 0,97 \\
\hline Freisa & & 1 \\
\hline Nebbiolo Chiavennasca & & 1 \\
\hline Pinot Nero & 1,29 & 0 \\
\hline Molinara & & 1,3 \\
\hline Dolcetto & & 1,45 \\
\hline Ancellotta & & 1,8 \\
\hline Schiava Grossa & & 1,94 \\
\hline Aleatico & 1,95 & \\
\hline Ciliegiolo & & 2,6 \\
\hline Uva Rara & 2,9 & \\
\hline Refosco Nostrano & & 2,9 \\
\hline Raboso Piave & 3,2 & 0 \\
\hline Barbera & 4,84 & 5 \\
\hline Negro Amaro & 7,74 & \\
\hline Sangiovese & 7,9 & 6,8 \\
\hline Lambrusco Maestri & & 9,4 \\
\hline Gamay & & 10 \\
\hline Cannonao/Grenache & 16,9 & \\
\hline Carmenère & & 20 \\
\hline Grignolino & & 25,2 \\
\hline Terrano & & 27,1 \\
\hline Uva di Troia & 27,74 & \\
\hline Monica & & 29,68 \\
\hline Cabernet Sauvignon & & 31,94 \\
\hline Croatina & 34 & 33,6 \\
\hline Lambrusco Salamino & 41,94 & 41,6 \\
\hline
\end{tabular}

On the other side, we highlight herewith the limitations of many other varieties, which, although considered to be of great value for the viticulture of certain terroirs, show a high susceptibility to esca, as we can see in many varieties investigated here, such as cv Albana, Glera (or Prosecco), Grechetto/Pignoletto, Istrian Malvasia, Manzoni Bianco, Riesling, Sauvignon, Trebbiano Toscano; Barbera, Cabernet Sauvignon, Carmenère, Corvina, Croatina, Dindarella, Lambrusco Salamino, Primitivo, Uva di Troia.

Despite the complexity of the phytopathologies of the vines, also with regard to possible synergistic effects with other harmful diseases, we can understand that, when given the possibility to plant grape varieties, well-known for their good or medium tolerance to esca, it will be easier to manage the health of the vineyards, to ensure their longevity and to achieve a better stability in yield.

\section{References}

[1] A. Graniti, Italia Agricola, 97, 543-550 (1960)

[2] G. Romanazzi, S. Murolo, L Pizzichini, S. Nardi, Il Mal dell'Esca della Vite. Atti Progetto Mesvit, ARSIA Regione Toscana, 143-149 (2010)

[3] M. Borgo, Il Mal dell'Esca della Vite. Atti Progetto Mesvit, ARSIA Regione Toscana, 186-190 (2010)

[4] A. Vercesi, Vignevini, 15 (4), 55-58 (1988) 